TM-1690

\title{
Description of a Small Commutation Spike Filter for D. C. Magnet Power Supplies
}

\author{
A. T. Visser \\ Fermi National Accelerator Laboratory \\ P.O. Box 500 \\ Batavia, Illinois 60510
}

October 1990 
TM-1690

Cat. \#2231.000

A.T. Visser

October 1990

DESCRIPTION OF A SMALL COMMUTATION SPIKE FILTER FOR D.C. MAGNET POWER SUPPLIES 
TABLE OF CONTENTS

\section{SUMMARY}

2. DESCRIPTION OF THE FILTER

3. ACKNOWLEDGEMENT

4. FIGURE 1 AND FIGURE 2 


\section{SUMMARY}

This note describes a small spike filter used to remove SCR commutation spikes from the d.c. output voltage of magnet power supplies. Removal of these spikes reduces the noise problems in electronic detectors installed in the same area. The filter is small enough to be mounted inside a power supply.

\section{DESCRIPTION OF THE FILTER}

All SCR controlled d.c. power supplies produce commutation spikes, which show up on the d.c. output voltage of the power supply. These spikes are generated when the power supply SCR's commutate from one phase to the next. There are usually 12 to 24 spikes per 60 cycle period produced by the 12 pulse magnet power supply. The magnitude of these spikes increases with the load current and changes for different power supply tap connections and operating voltages. A typical spike looks like a severely damped and distorted $10 \mathrm{kHz}$ to $500 \mathrm{kHz}$ oscillation with a peak voltage of about $100 \mathrm{~V}$ (Fig. 1).

These spikes are harmless for the power supplies. Power supply ripple filters would remove them, but are not used for economical reasons. These spikes could be removed by installing small L-C type filters at the d.c. output. However, even small L-C filters become large when the inductor has to carry $2500 \mathrm{~A}$ to $5000 \mathrm{~A}$. Putting steel cores around the power supply output conductors yields about $5 \times 10^{-6} \mathrm{H}$ per 80 lbs core at 2500 Adc. It may be concluded that using external inductors is costly, requires floor space and creates extra losses. It is not practical in many congested experimental area installations.

All power supplies have however some internal stray inductance at their output terminals. The amount of inductance depends on the tap connections but could be 10 to $100 \mu \mathrm{H}$. It is also true that the high frequency commutation spike is the main source of noise and not the $720 \mathrm{~Hz}$ ripple present in the d.c. output. A capacitor working against the power supply internal inductance could effectively reduce the positive going commutation spike. The filter must be able to withstand the ripple currents created by $720 \mathrm{~Hz}$ and higher harmonics. The $720 \mathrm{~Hz}$ ripple voltage could be as high as $120 \mathrm{~V}$ for a $400 \mathrm{Vdc}$ power supply.

The filter shown in Fig. 2 was installed in two power supplies at the experimental area in Proton East (TPL, X791) because of acute noise problems. Figure 1 shows the commutation spikes with and without the filter at a $500 \mathrm{~kW}$ power supply at about $1800 \mathrm{~A}, 70 \mathrm{Vdc}$. These filters reduced the commutation spikes substantially and improved the experimental data taken by an estimated factor 5 to 10. 
The filter uses a diode and a bleeder resistor of $10 \Omega$ to reduce the $720 \mathrm{~Hz}$ ripple current through the filter capacitor but is still able to suppress the positive commutation spike. Other power supplies or power supply tap settings may not produce such good results.

Future filters will be made from somewhat smaller components and will be mounted inside the power supply enclosure. They cost about $\$ 100$ each.

\section{ACKNOWLEDGEMENT}

I am grateful to Julius Lentz who did many tests and packaged the final filter. 


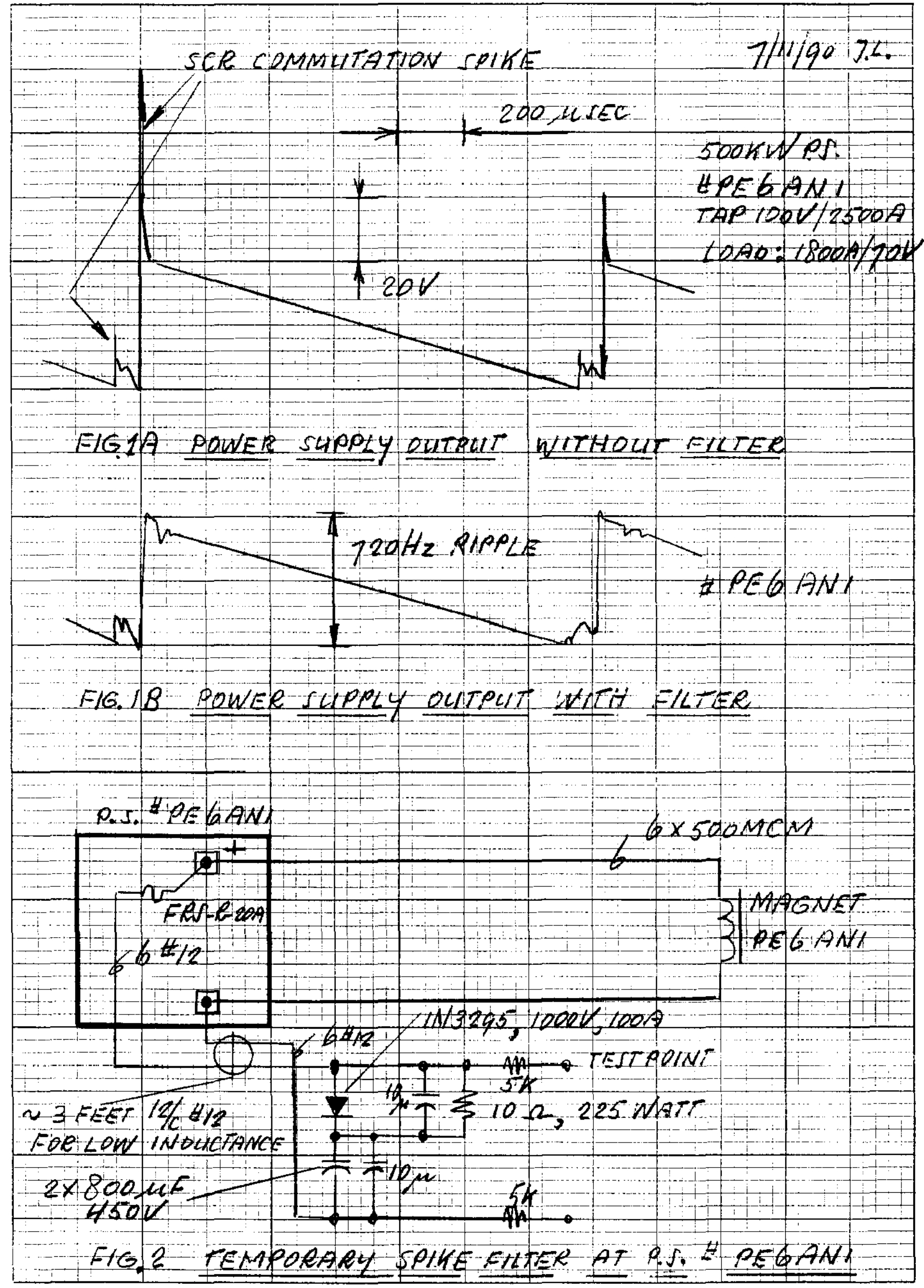

